\title{
Supervised Intelligent Committee Machine Method for Hydraulic Conductivity Estimation
}

\author{
Gokmen Tayfur • Ata A. Nadiri • Asghar A. Moghaddam
}

Received: 23 October 2013 / Accepted: 5 February 2014 /

Published online: 17 February 2014

(C) Springer Science+Business Media Dordrecht 2014

\begin{abstract}
Hydraulic conductivity is the essential parameter for groundwater modeling and management. Yet estimation of hydraulic conductivity in a heterogeneous aquifer is expensive and time consuming. In this study; artificial intelligence (AI) models of Sugeno Fuzzy Logic (SFL), Mamdani Fuzzy Logic (MFL), Multilayer Perceptron Neural Network associated with Levenberg-Marquardt (ANN), and Neuro-Fuzzy (NF) were applied to estimate hydraulic conductivity using hydrogeological and geoelectrical survey data obtained from Tasuj Plain Aquifer, Northwest of Iran. The results revealed that SFL and NF produced acceptable performance while ANN and MFL had poor prediciton. A supervised intelligent committee machine (SICM), which combines the results of individual AI models using a supervised artificial neural network, was developed for better prediction of the hydraulic conductivity in Tasuj plain. The performance of SICM was also compared to those of the simple averaging and weighted averaging intelligent committee machine (ICM) methods. The SICM model produced reliable estimates of hydraulic conductivity in heterogeneous aquifers.
\end{abstract}

Keyword Hydraulic conductivity - Artificial intelligence methods · Supervised intelligence committee machine $\cdot$ Tasuj plain $\cdot$ Heteregenous aquifer

\section{Introduction}

Estimation of hydrogeological parameters is crucial for managing groundwater resources, contaminant transport, and designing remediation measures. Variety of numerical models were developed for parameter estimation, such as hydraulic conductivity, porosity, soil water retention (Tsai and Li 2008). However, due to some limitations of the numerical models such

G. Tayfur $(\triangle)$

Department of Civil Engineering, Izmir Institute of Technology, Izmir, Turkey e-mail: gokmentayfur@iyte.edu.tr

A. A. Nadiri

Department of Geology, University of Tabriz, Tabriz, Iran e-mail: Nadiri@tabrizu.ac.ir

A. A. Moghaddam

Department of Geology, Faculty of Science, University of Tabriz, Tabriz, Iran 
as low flexibility, high complexity, cost, and time consuming, other methodologies such as artificial intelligence (AI) models were recently developed for this purpose.

Hitherto, artificial intelligence (AI) models such as fuzzy logic (FL) (Bárdossy and Disse, 1993; Batyrshin et al. 2005; Tutmez and Hatipoglu 2007; Chu and Chang 2009; Helmy et al. 2010; Anifowose and Abdulraheem 2011; Tayfur 2012; Morankar et al. 2013), artificial neural network (ANN) (Schaap and Leij 1998; Merdun et al. 2006; Nayak et al. 2006; Samani et al. 2007; Tayfur et al. 2007; Mohanty et al. 2010; Motaghian and Mohammadi 2011; Shirmohammadi et al. 2013;), and neuro-fuzzy (NF) (Tutmez 2010; Huang et al. 2010; Moosavi et al. 2013; Safavi et al. 2013) have gained popularity for the hydrogeological parameter estimation.

Hydrogeological parameters such as hydraulic conductivity are not clear-cut and most of the time they are associated with uncertainties. Hence, for hydraulic conductivity estimation, the researchers have tried to evaluate different AI methods with various abilities such as fuzzy logic (FL) (Ross et al. 2007; Olatunji et al. 2011; Colin et al. 2011), artificial neural network (ANN) (Tamari et al. 1996; Garcia and Shigidi 2006; Sun et al. 2011; Inan and Tayfur 2012; Gaur et al. 2013), and neuro-fuzzy (NF) (Malki and Baldwin 2002; Hurtado et al. 2009; Sezer et al. 2010; Dhar and Patil 2012).

Generally, more than one AI model provides a similar acceptable fit to the observations (Tayfur and Singh 2011). Therefore, usage of multi-model interface can be advantages. For hydraulic conductivity estimation, intelligent committee machine (ICM) which is an artificial intelligence multi-model interface and used in different disciplines (Lim 2005; Chen and Lin 2006) can be utilized. The ICM uses the results of AI models in order to arrive at overall decision that is supposed to be superior to that of any individual AI model acting alone (Hornik et al. 1989; Naftaly et al. 1997).

The ICM can combine AI model results with a simple averaging (Naftaly et al. 1997; Chen and Lin 2006) or by weighted averaging. Using simple averaging produces the final output by linearly combining the outputs of individual AI models through the same weights. Although, it can produce better results, the AI models should have different weights based on their efficiencies. Using weighted averaging ascribes different weights to AI models which are generally optimized by genetic algorithm (GA) (Kadkhodaie-Ilkhchi et al. 2009; Labani et al. 2010) to find the best fit of the ICM output to the measurements. This method has linear nature to combine the AI models.

Instead of linearly combining AI model results, this study introduces a supervised intelligent committee machine (SICM) that replaces linear combination with artificial neural network (ANN). In SICM, the ANN receives individual model estimations as input and derives a new estimation.

Each AI method has its advantages and disadvantages. For example; ANN is a powerful tool for performing nonlinear input - output mapping. However, it is a black-box model which cannot reveal insight into understanding the physics of the process. It is a good interpolator but a poor extrapolator. MFL is a fuzzy rule based method requiring construction of many fuzzy rules, which can be unattractive from a practical point of view. Yet, it is attractive since it can account for ambiguities, and uncertainity and it is more in line with human thinking since it uses verbal statetments. SFL also operates like MFL with fuzzy rules that contain mathematical expressions. Hence, this method requires parameter estimation, which cannot be always an easy task. NF in a way combines ANN and FL methods. The objective of this study is to reap advantages of each AI method by employing the SICM to predict the very fundamental aquifer parameter of hydraulic conductivity. Thus, this study, using the SICM, accomplished the estimation of hydraulic conductivity in unconfined and heterogeneous Tasuj aquifer. 


\section{Study Area}

The Tasuj plain, which is about $302.67 \mathrm{~km}^{2}$, is a subbasin of Urmia Lake basin (Fig. 1) and located in the northwestern part of Tabriz city in Iran. The study area is surrounded by Urmia Lake (south), Mishu Mountains (north), Salmas Plain (west) and Shabestar Plain (east). The prevailing climate in the Tasuj plain is semiarid-cold (Nadiri et al. 2013). Average annual precipitation is about $232.7 \mathrm{~mm}$ (based on measurements at Tasuj climatological station, 2000-2009) (Research Center of Agriculture and Natural Resources of East Azerbaijan Province 2010). In the Tasuj basin, there is no permanent river and there is only a few seasonal rivers originating from Mishu Mountains. Agriculture is the main economic activity in Tasuj City and 15 villages in the study area. The main source for drinking, industrial and agricultural demands in the plain is groundwater.

The Tasuj plain aquifer is a heterogeneous and unconfined and the groundwater in the aquifer was withdrawn through 147 water wells, 70 springs and 70 qanats (Nadiri et al. 2013). The 24 springs and 14 qanats became dry in the recent years due to over-drawing. Therefore, identification of hydrogeological parameters such as hydraulic conductivity in the study area is

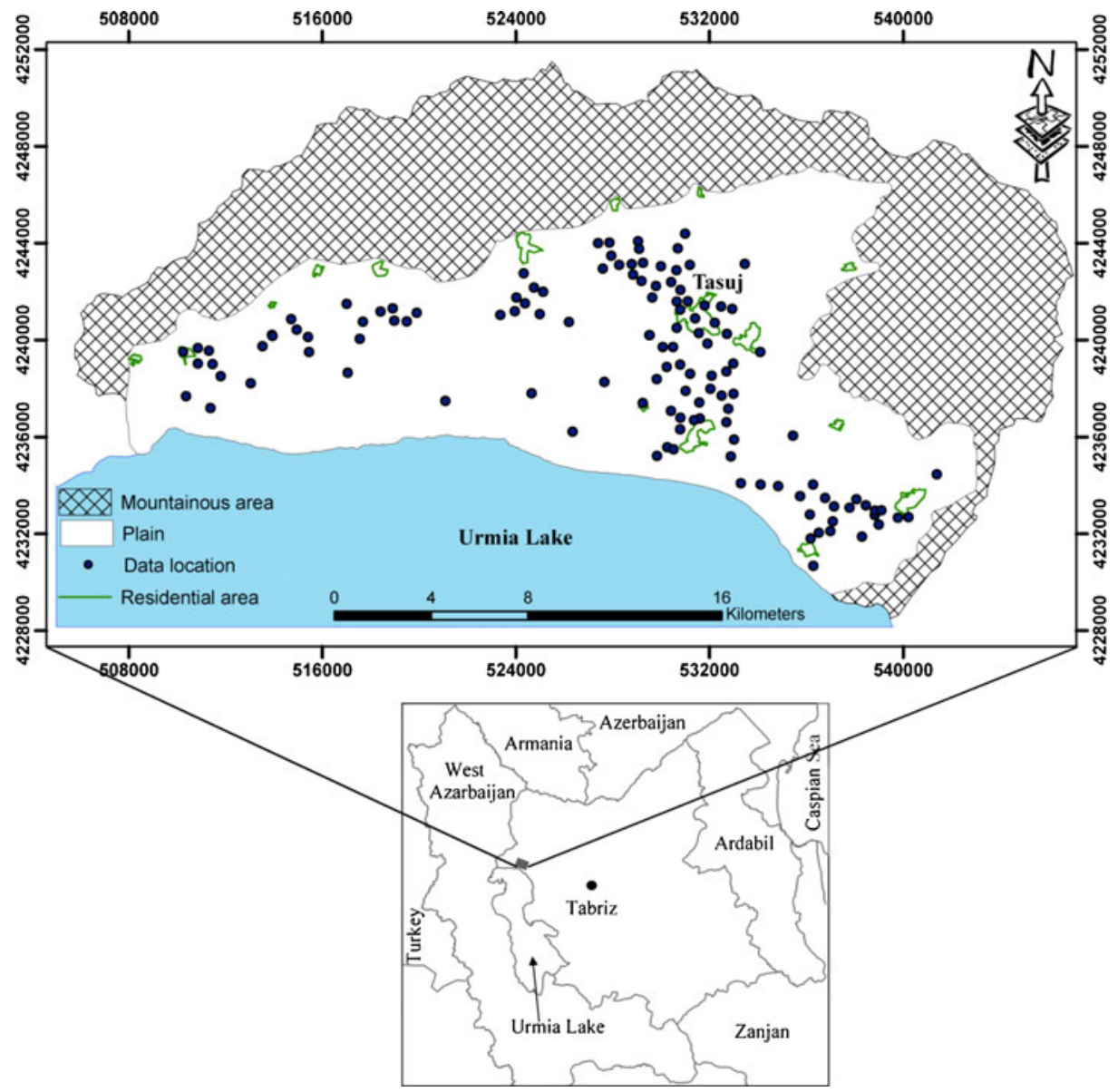

Fig. 1 Tasuj Plain and locations of hydraulic conductivity measurment 
vital for groundwater management. More information about the study area is given in Nadiri et al. (2013).

Based on the a geo-electrical survey that was conducted by the Abkav Consulting Engineering Co. (1973), the saturated zone thickness in the aquifer (B) and transverse resistance $\left(R_{t}\right)$ were estimated at 63 points. The maximum thickness is $182 \mathrm{~m}$ and the minimum thickness is $44 \mathrm{~m}$. To estimate $\mathrm{K}$ values in each point, both parameters are needed. Therefore, $\mathrm{B}$ and $R_{t}$ distributions were obtained by an ordinary kriging method.

Hydraulic conductivity in the saturated zone is related to electrical resistivity $(\rho)$ which is the transverse resistance $\left(R_{t}\right)$ divided by the thickness of the saturated zone $(B)$. The electrical resistivity $(\rho)$, on the other hand, depends on the salinity of formation water (Putvance 2000). Therefore, the electrical conductivity (EC), which responds to the salinity of formation water, is also related to hydraulic conductivity. Hence, in this study B, EC, and O, which is the distance of each estimation point to the position of down corner of the right side of the study area map (see Fig. 1) to take into account the geological and geomorphological effects, are used as input variables for the AI models.

In 132 locations of Tasuj unconfined aquifer, hydraulic conductivity was determined by the constant and step drawdown pumping tests that were carried out by the water resources authority of East Azarbaijan (Fig. 1). The maximum $\mathrm{K}$ is $9.74 \mathrm{~m} /$ day and the minimum $\mathrm{K}$ is $0.13 \mathrm{~m} /$ day. The mean and the standard deviation of $\mathrm{K}$ are 2.35 and $3.30 \mathrm{~m} /$ day, respectively (Nadiri et al. 2013).

\section{Models}

\subsection{Fuzzy Logic (FL)}

In fuzzy set theory, each element may belong to a set to a degree which can take values ranging from 0 to 1 (Zadeh 1965). The key idea in fuzzy logic is the allowance of partial belongings of any object to different subsets of a universal set. Fuzzy sets have ambiguous boundaries and gradual transitions between defined sets and this makes it to be appropriate to deal with the nature of uncertainty (Calvo and Estrada 2009). Each fuzzy set is represented by a membership function (MF), which can be Gaussian, triangular, or trapezoidal. Intuition, rank ordering, and inductive reasoning can be, among many, ways to assign membership functions to fuzzy variables. The intuitive approach is instead used commonly because it is simple and derived from the innate intelligence and understanding of human beings.

A FL model consists of four main parts i.e., Fuzzifier, Inference Engine, Fuzzy Rule Base, and Defuzzifier (Tayfur 2012). Fuzzification forms fuzzy sets for input-output variables using membership functions. The fuzzy rule base contains rules that include all possible fuzzy relations between inputs and outputs. These rules are expressed in the IF-THEN format. In the Mamdani Fuzzy Logic (MFL) rule system both antecedent and consequent parts of a rule contain verbal statements. In Sugeno Fuzzy Logic (SFL), the consequent part of the rule contains mathematical expressions, relating output variable to input variables. The fuzzy inference engine takes into account all the fuzzy rules in the fuzzy rule base and learns how to transform a set of inputs to corresponding outputs that are composed to form a single fuzzy subset for the output variable. Defuzzification converts the resulting fuzzy output from the fuzzy inference engine to a number. The details of MFL can be obtained from Mamdani and Assilian (1975), Mamdani (1976, 1977) and Tayfur (2012). The details of SFL can be found elsewhere (Takagi and Sugeno 1985; Sugeno 1985; Akbari et al. 2009). 


\subsection{Artificial Neural Network (ANN)}

Artificial neural networks are imitating human brain by using mathematical methods and have been proven to be beneficial tools for simulating, predicting and forecasting hydrological variables (Nadiri 2007; Nourani et al. 2008b; Piotrowski and Napiorkowski 2011; Siou et al. 2011; Tayfur 2012). The most widely used neural network is the multi-layer perceptron (MLP) (Hornik et al. 1989; Haykin 1999; Sulaiman et al. 2011; Fijani et al. 2012; Mustafa et al. 2012). In the MLP, as a feed forward ANN, the neurons are organized in layers and each neuron is connected fully with neurons in the next layer. A typical three-layer feedforward neural network (FFNN) is shown in Fig. 2, where the input signal propagates through the network in a forward direction. In a FFNN, the input quantities $\left(x_{i}\right)$ are fed into the input layer neurons which, in turn, pass them on to the hidden layer neurons $\left(z_{i}\right)$ after multiplying them by the connection weights $\left(v_{i j}\right)$ (Fig. 2). A hidden layer neuron adds up the weighted input received from each input neuron $\left(x_{i} v_{i j}\right)$, associates it with a bias $\left(b_{j}\right)$, and then passes the result $\left(n e t_{j}\right)$ on through the activation function. Similarly, the produced outputs from the inner neurons are passed to the network output neuron. The net information received by the output neuron from the inner neurons is passed through the activiation function to produce the network output. The optimal weights are found by minimizing a predetermined error function $(E)$ of the following form (ASCE 2000):

$$
E=\sum_{\mathrm{P}} \sum_{\mathrm{p}}\left(y_{i}-t_{i}\right)^{2}
$$

where $\mathrm{yi}=$ the component of an ANN output vector $\boldsymbol{Y} ; t_{i}=$ the component of a target output vector $\boldsymbol{T} ; p=$ the number of output neurons; and $P=$ the number of training patterns. The gradient-descent method, along with the chain rule of differentiation, is generally employed to modify the network weights as (Tayfur 2012):

$$
\Delta v_{i j}(n)=-\delta \frac{\partial E}{\partial v_{i j}}+\alpha \Delta v_{i j}(n-1)
$$

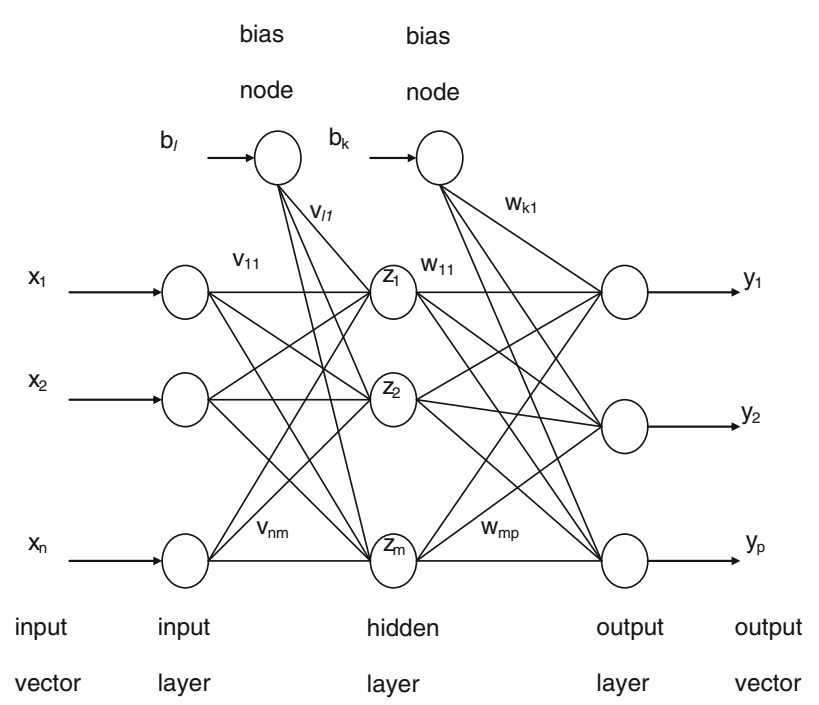

Fig. 2 A typical feedforward ANN model 
where $\Delta v_{i j}(n)$ and $\Delta v_{i j}(n-1)=$ the weight increments between node $i$ and $j$ during the $n^{\text {th }}$ and $(n-1)^{\text {th }}$ pass or epoch; $\delta=$ the learning rate; and $\alpha=$ the momentum factor.

This study adopted the hyperbolic tangent activation function (Tayfur 2012) and the training algorithm of Levenberg-Marquardt (LM) (Daliakopoulos et al. 2005; Nourani et al. 2008a, 2008b; Mustafa et al. 2012).

\subsection{Neuro-Fuzzy (NF)}

Neuro-fuzzy modeling is a combination technique for describing the behavior of a system using fuzzy inference rules within a neural network structure. The NF inference system consists of a given input/output data set and SFL whose MF parameters are tuned using a hybrid algorithm (Wolkenhauer 2001; Sanikhani and Kisi 2012). The most compatible method for construction of NF model is Sugeno method using subtractive clustering.

In this study, the NF architecture of a five-layer MLP network was considered in the hydraulic conductivity estimation. In the first layer, membership function of input data were generated like the SFL model. Also, a generalized Gaussian function was used to develop membership functions. In the second layer, the firing strength was calculated for the each rule via multiplication. In the third layer the normalized firing strengths were computed for each neuron. The contribution of the each rule in the model output was calculated based on the first order SFL method in the forth layer. Lastly, the final output as the weighted average of all rule outputs (aggregation) was calculated in the fifth layer. The NF parameters and membership function parameters were estimated using the hybrid algorithm, which is a combination of the gradient descent and least-squares method (Aqil et al. 2007; Akrami et al. 2013).

\subsection{SICM Model}

The Intelligent committee machine approach combines the artificial intelligence model results to reap advantages of all AI models to produce final output. Previous works recommended two methods of the simple averaging and the weighted averaging for construction of SICM model (Chen and Lin 2006; Labani et al. 2010). This study instead introduces a supervised intelligent committee machine (SICM) model that employs ANN as a supervised combiner of AI models.

The SICM model consists of four artificial intelligence models shown in Fig. 3 and includes two major steps. In the first step, hydraulic conductivity is estimated using the artificial intelligence models including MFL, SFL, ANN and NF. In the second step, a supervised

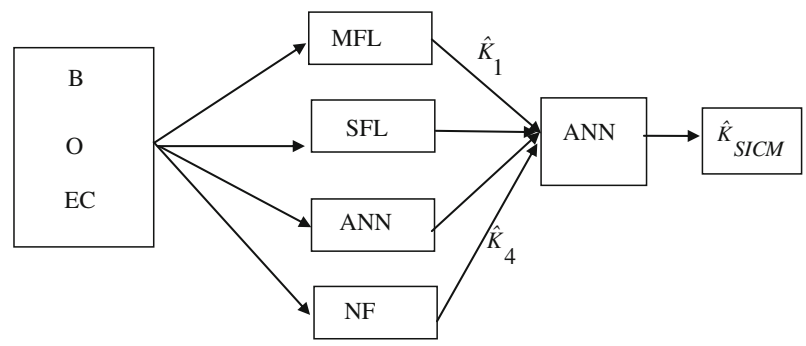

Fig. 3 The Schematic structure of SICM model 
artificial neural network is constructed as a nonlinear and supervised combiner. The mathematical expression of the SICM model can be expressed as follows:

$$
\widehat{K}_{i}=A I_{i}(O, E C, B)
$$

$\widehat{K}_{i}$ is the output of the each AI model which is used as $i^{\text {th }}$ input to the SICM model.

\section{Model Calibration and Testing}

\subsection{Mamdani Fuzzy Model}

Fuzzy c-means (FCM) clustering for MFL (Arrell et al. 2007; Kannan et al. 2012) was used for the construction of a fuzzy rule base (Li et al. 2001). Gaussian membership functions were employed for the input variables. Results showed that the optimum number of clusters for the hydraulic conductivity is 12 . The parameters of Gaussian membership function are summarised in Table 1. The model was calibrated with 105 data sets, with the root mean square (RMSE) of $1.21 \mathrm{~m} /$ day and the determination coefficient $\left(\mathrm{R}^{2}\right)$ of 0.77 . The model was then tested against 27 data sets, with a performance of $\mathrm{RMSE}=1.89 \mathrm{~m} /$ day and $\mathrm{R}^{2}=0.63$.

\subsection{Sugeno Fuzzy Model}

Subtractive Clustering (SC) for SFL (Chiu 1994) was applied for the data clustering. Radius clustering was selected based on the minimum RMSE. Choosing a value of 0.4 for clustering radius was associated with the lowest RMSE of $0.99 \mathrm{~m} /$ day which generated six fuzzy IFTHEN rules. The model was calibrated with 105 data sets with $\mathrm{RMSE}=0.98 \mathrm{~m} /$ day and the $\mathrm{R}^{2}=0.77$. The model was then tested against 27 data sets, with a performance of $\mathrm{RMSE}=$ $1.67 \mathrm{~m} /$ day and $\mathrm{R}^{2}=0.72$.

Table 1 The parameters of Gaussian membership functions for MFL model ( $\sigma$ : standard daviation of normal distribution, c: mean of data)

\begin{tabular}{|c|c|c|c|c|c|c|c|c|}
\hline \multirow{2}{*}{$\begin{array}{l}\text { Input } \\
\text { Parameter MF No. }\end{array}$} & \multicolumn{2}{|l|}{$\mathrm{O}(\mathrm{m})$} & \multicolumn{2}{|c|}{ EC(micro.s/cm) } & \multicolumn{2}{|l|}{$\mathrm{B}(\mathrm{m})$} & \multicolumn{2}{|c|}{ Output $\widehat{K} \quad(\mathrm{~m} / \mathrm{d})$} \\
\hline & $\sigma$ & $\mathrm{c}$ & $\sigma$ & $\mathrm{c}$ & $\sigma$ & $\mathrm{c}$ & $\sigma$ & $\mathrm{c}$ \\
\hline 1 & 2525 & 19220 & 277.5 & 2429 & 5.565 & 106.8 & 0.6044 & 0.6074 \\
\hline 2 & 1995 & 22710 & 121.1 & 1530 & 16.53 & 158.8 & 0.7073 & 0.3167 \\
\hline 3 & 1880 & 31900 & 132.2 & 1454 & 6.123 & 114.2 & 0.7032 & 1.353 \\
\hline 4 & 1613 & 30370 & 164.5 & 1123 & 6.295 & 119 & 1.13 & 3.588 \\
\hline 5 & 1885 & 23880 & 205.1 & 2002 & 8.147 & 98.35 & 0.8993 & 2.489 \\
\hline 6 & 2404 & 34400 & 145.8 & 1631 & 6.715 & 93.75 & 1.405 & 4.262 \\
\hline 7 & 2740 & 17900 & 293.6 & 2516 & 5.229 & 110.1 & 0.6001 & 0.565 \\
\hline 8 & 1498 & 27840 & 135.2 & 1432 & 7.986 & 109 & 1.717 & 4.129 \\
\hline 9 & 3905 & 12250 & 140.5 & 1501 & 5.48 & 98.53 & 0.4931 & 1.445 \\
\hline 10 & 1448 & 27720 & 122.5 & 1301 & 6.438 & 98.87 & 0.6457 & 11.31 \\
\hline 11 & 1480 & 29090 & 141.6 & 1279 & 7.187 & 109.9 & 1.162 & 3.688 \\
\hline 12 & 3154 & 15720 & 304.5 & 2497 & 6.596 & 107.5 & 0.6449 & 1.122 \\
\hline
\end{tabular}




\subsection{Artificial Neural Network (ANN)}

A three layer network with Levenberg-Marquardt (LM) training algorithm, which is denoted as MLP-LM, was used for K estimation. The training was accomplished with RMSE $=1.03 \mathrm{~m} /$ day and $\mathrm{R}^{2}=0.82$. The testing performance was $\mathrm{RMSE}=1.85 \mathrm{~m} /$ day and $\mathrm{R}^{2}=0.63$.

\subsection{Neuro-Fuzzy(NF)}

The same clusters of input and outputs and rules were used for NF construction. The hybrid algorithm which is a combination of the least-squares method and the back propagation gradient descent method was applied to optimize and adjust Gaussian membership function parameter and the coefficients of output linear equation (Zounemat-Kermani and Teshnehlab 2008). $\mathrm{RMSE}=0.83 \mathrm{~m} /$ day and $\mathrm{R}^{2}=0.85$ for the training and $\mathrm{RMSE}=1.51 \mathrm{~m} /$ day and $\mathrm{R}^{2}=$ 0.76 for the testing stages were obtained.

Based on the above RMSE and $\mathrm{R}^{2}$ results; it can be stated that MFL and ANN showed poor performance compared to those of SFL and NF models. At this stage, we can take advantage of using the supervised intelligence committee machine (SICM) to obtain better estimations of $\mathrm{K}$ values.

\section{SICM Model}

\subsection{SICM Model Training and Testing}

The SICM method shown in Fig. 3 adopts a simple ANN method to re-estimate hydraulic conductivity values, predicted by the SFL, MFL, ANN, and NF in the training step (105 sample data). The ANN model had 4 neurons $(\widehat{K}$ via SFL, MFL, ANN, and NF) in the input layer, three neurons in the hidden layer and single neuron in the output layer for the target $\widehat{K}_{\text {SICM }}$. The network was successfully trained with 500 epochs and RMSE of $0.42 \mathrm{~m} /$ day. Then, the SICM model was tested against 27 data sets. The RMSE and $\mathrm{R}^{2}$ for SICM predictions were computed as $0.62 \mathrm{~m} /$ day and 0.94 , respectively. Comparing the error measure values with those of individual models above, it is seen that SICM outperforms individual AI models with low RMSE and high $\mathrm{R}^{2}$ values. This result implies that SICM model shows high performance for predicting the hydraulic conductivity values in the heterogeneous unconfined aquifer in Tasuj Plain. Figure 4 shows the distribution of $\mathrm{K}$ in Tasuj Plain which was interpolated from the estimated values by the SICM model.

\subsection{Comparative Analysis}

Here, SICM model performance was compared against that of the ICM model. For the simple averaging method, the ICM estimated hydraulic conductivity using SFL, MFL, ANN, and NF with equal weights as follows:

$$
\widehat{K}_{S I C M}=0.25 \widehat{K}_{S F L}+0.25 \widehat{K}_{M F L}+0.25 \widehat{K}_{A N N}+0.25 \widehat{K}_{N F}
$$

For the weighted averaging method, optimal weights, $w_{i}$ were determined by minimizing the mean squared error (MSE):

$$
M S E=\sum_{i=1}^{m} \frac{1}{m}\left(w_{1} \widehat{K}_{i, S F L}+w_{2} \widehat{K}_{i, M F L}+w_{3} \widehat{K}_{i, A N N}+w_{4} \widehat{K}_{i, N F}-K_{i}\right)^{2}
$$




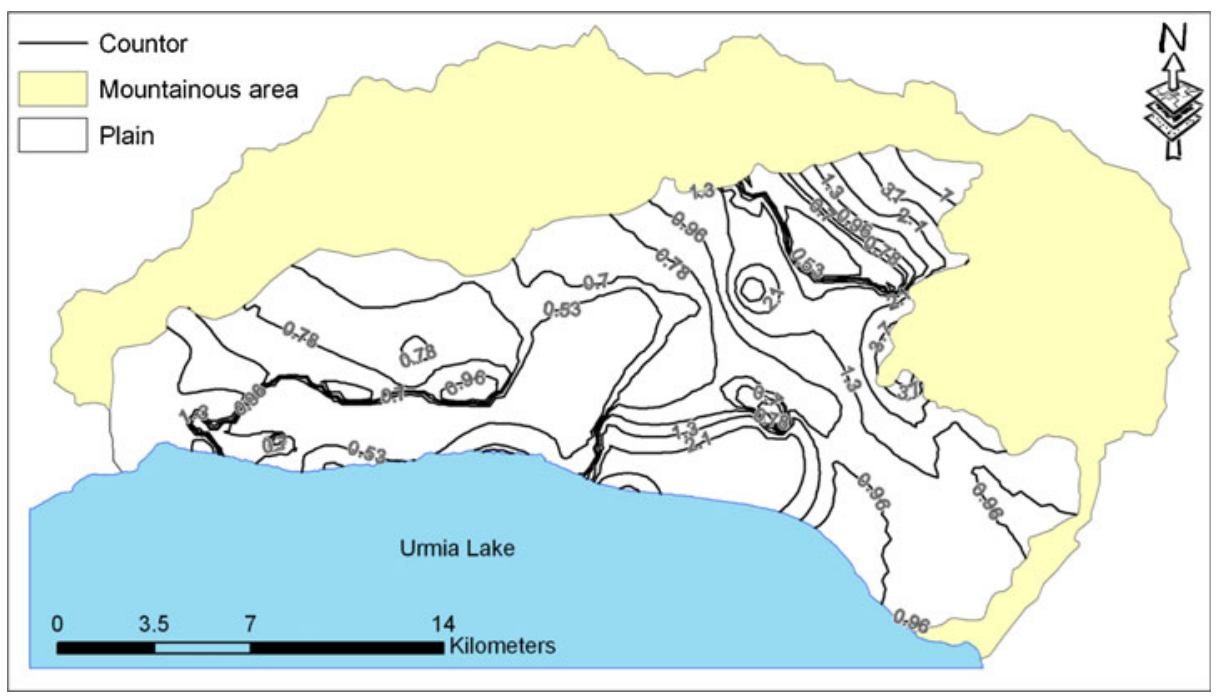

Fig. 4 Distribution of estimated hydraulic conductivity via SICM model

where $m$ is the number of training data (105 samples). The weights, $w_{i}$ range between 0 and 1 and the sum of weights is unity, $\sum_{i} w_{i}=1$.

A GA optimizer in MATLAB toolbox was used to minimize the MSE. The initial population size was set to 25 . The maximum number of generations went up to 140 . The probability for crossover operation was $80 \%$ and the mutation function was Gaussian. After optimal weights were obtained by GA, the ICM model estimated hydraulic conductivity by the following equation:

$$
\widehat{K}_{C M I S}=0.27 \widehat{K}_{S F L}+0.17 \widehat{K}_{M L F}+0.21 \widehat{K}_{A N N}+0.34 \widehat{K}_{N F}
$$

The performance results of the SICM and ICM are shown in Table 2 for K data for the testing stage. As seen, the SICM better performed than the ICM, which in turn also outperformed the individual models, presented above. According to Table 2, ICM with weighted averaging performs better than ICM with simple averaging, which agrees to Kadkhodaie-Ilkhchi et al. (2009) and Labani et al. (2010).

\section{Conclusions}

This study introduced a supervised intelligent committee machine (SICM) algorithm, which combines the outcomes of individual AI models, to predict the hydraulic conductivity of Tasuj aquifer. In SICM, the ANN receives predictions of four individual models-Sugeno fuzzy

Table 2 Performance measures for SICM and ICM (testing stage)

\begin{tabular}{lccc}
\hline Criteria & SICM & ICM with simple averaging & ICM with weighted averaging \\
\hline $\mathrm{R}^{2}$ & 0.94 & 0.83 & 0.87 \\
$\mathrm{RMSE}(\mathrm{m} / \mathrm{d})$ & 0.62 & 1.40 & 1.28 \\
\hline
\end{tabular}


logic (SFL), Mamdani fuzzy logic (MFL), neuro-fuzzy (NF), and artificial neural network $(\mathrm{ANN})-$ as input and derives a new estimation.

Following conclusions can be drawn from this study:

1. MFL and ANN showed poor performance compared to those of SFL and NF models in predicting hydraulic conductivity values. It can be stated that SFL and NF are more applicable for the estimation of hydraulic conductivity in the heterogeneous and unconfined Tasuj aquifer.

2. SICM model can be employed to predict hydraulic conductivity values.

3. ICM and SICM models produced better performance than the individual ones.

4. The SICM is more capable than ICM in predicting hydraulic conductivities of the heterogeneous and unconfined aquifer, Tasuj plain, as a case study.

5. Most of the aquifers in nature are heterogeneous and complex. Therefore, the presented method (SICM) can be used for prediction of different hydrogeological parameters such as porosity, water content and etc., in various case studies.

Note that in SICM method, the main focus is to maximize the performance by optimizing the weights assigned to each AI model. Yet, the main limitation of this method is that it cannot consider the parsimony and uncertainty of the assigned weights to individual models, which can be researched in future. Also, the influence of Kriging interpolation of B and Rt on the output of AI models was not investigated in this study. It could be a topic of a future research.

\section{References}

Abkav Consulting Engineering Company (1973) Geophysical studies reports of Tabriz, Tasuj and Shabestar plains. East Azerbaijan Regional Water Authority, Persian

Akbari M, Afshar A, Sadrabadi MR (2009) Fuzzy rule based models modification by new data: application to flood flow forecasting. Water Resour Manag 23(12):2491-2504

Akrami SA, Shafie A, Jaafar O (2013) Improving rainfall forecasting efficiency using modified adaptive neurofuzzy inference system (MANFIS). Water Resour Manag 27(9):3507-3523

Anifowose F, Abdulraheem A (2011) Fuzzy logic-driven and SVM-driven hybrid computational intelligence models applied to oil and gas reservoir characterization. J Nat Gas Sci Eng 3(3):505-517

Aqil M, Kita I, Yano A, Nishiyama S (2007) Analysis and prediction of flow from local source in a river basin using a neuro-fuzzy modeling tool. J Environ Manag 85(1):215-223

Arrell KE, Fisher PF, Tate NJ, Bastin L (2007) A fuzzy c-means classification of elevation derivatives to extract the morphometric classification of landforms in Snowdonia, Wales. Comput Geosci 33:1366-1381

ASCE Task Committee on Application of Artificial Neural Networks in Hydrology (2000) Artificial neural network in hydrology, part I and II. J Hydrol Eng 5:115-137

Bárdossy A, Disse M (1993) Fuzzy rule-based models for infiltration. Water Resour Res 29(2):373-382

Batyrshin I, Sheremetov L, Markov M, Panova A (2005) Fuzzy rule-based models for infiltration hybrid method for porosity classification in carbonate formations. J Pet Sci Eng 47:35-50

Calvo PI, Estrada GJC (2009) Improved irrigation water demand forecasting using a soft-computing hybrid model. Biosyst Eng 102(2):202-218

Chen CH, Lin ZS (2006) A committee machine with empirical formulas for permeability prediction. Comput Geosci 32:485-496

Chiu S (1994) Fuzzy model identification based on cluster estimation. J Intell Fuzzy Syst 2:267-278

Chu HJ, Chang LC (2009) Application of optimal control and fuzzy theory for dynamic groundwater remediation design. Water Resour Manag 23(4):647-660

Colin F, Guillaume S, Tisseyre B (2011) Small catchment agricultural management using decision variables defined at catchment scale and a fuzzy rule-based system: a Mediterranean vineyard case study. Water Resour Manag 25(11):2649-2668

Daliakopoulos IN, Coulibaly P, Tsanis IK (2005) Groundwater level forecasting using artificial neural networks. J Hydrol 309:229-240 
Dhar A, Patil RS (2012) Multiobjective design of groundwater monitoring network under epistemic uncertainty. Water Resour Manag 26(7):1809-1825

Fijani E, Chitsazan N, Nadiri AA, Asghari MAA, Tsai, FTC (2012) Hierarchical bayesian model averaging for nonuniqueness and uncertainty analysis of artificial neural networks. AGU Fall Meeting, San Francisco, USA

Garcia LA, Shigidi A (2006) Using neural networks for parameter estimation in groundwater. J Hydrol 318(1-4): 215-231

Gaur S, Ch S, Graillot D, Chahar BR, Kumar DN (2013) Application of artificial neural networks and particle swarm optimization for the management of groundwater resources. Water Resour Manag 27(3):927-941

Haykin S (1999) Neural networks, a comprehensive foundation. Macmillan College Publishing, New York

Helmy T, Fatai A, Faisal K (2010) Hybrid computational models for the characterization of oil and gas reservoirs. Expert Syst Appl 37(7):5353-5363

Hornik K, Stinchcombe M, White H (1989) Multilayer feedforward networks are universal approximators. Neural Netw 2:359-366

Huang Y, Gedeon TD, Wong PM (2010) An integrated neural-fuzzy-genetic-algorithm using hyper-surface membership functions to predict permeability in petroleum reservoirs. Eng Appl Artif Intell 14(1):15-21

Hurtado N, Aldana M, Torres J (2009) Comparison between neuro-fuzzy and fractal models for permeability prediction. Comput Geosci 13:181-186

Inan T, Tayfur G (2012) A prediction model for the level of well water. Sci Res Essays 7(50):4242-4252

Kadkhodaie-Ilkhchi A, Rezaee MR, Rahimpour-Bonab H (2009) A committee neural network for prediction of normalized oil content from well log data: An example from south pars gas field, Persian Gulf. J Pet Sci Eng 65:23-32

Kannan SR, Ramathilagam S, Chung PC (2012) Effective fuzzy c-means clustering algorithms for data clustering problems. Expert Syst Appl 39:6292-6300

Labani MM, Kadkhodaie-Ilkhchi A, Salahshoor K (2010) Estimation of NMR log parameters from conventional well log data using a committee machine with intelligent systems: A case study from the Iranian part of the south pars gas field, Persian Gulf Basin. J Pet Sci Eng 72:175-185

Li H, Philip CCL, Huang HP (2001) Fuzzy neural intelligent systems: Mathematical foundation and the applications in engineering. CRC Press, Boca Raton

Lim JS (2005) Reservoir properties determination using fuzzy logic and neural networks from well data in offshore Korea. J Pet Sci Eng 49:182-192

Malki HA, Baldwin J (2002) A neuro-fuzzy based oil/gas producibility estimation method. IEEE Int Jt Conf Neural Netw 1:896-901

Mamdani EH (1976) Advances in the linguistic synthesis of fuzzy controllers. Int J Man Mach Stud 8:669-678

Mamdani EH (1977) Applications of fuzzy logic to approximate reasoning using linguistic synthesis. IEEE Trans Comput 26:1182-1191

Mamdani EH, Assilian S (1975) An experimental in linguistic synthesis with a fuzzy logic control. Int J Man Mach Stud 7:1-13

Merdun H, Inar OC, Meral R, Apan M (2006) Comparison of artificial neural network and regression pedotransfer functions for prediction of soil water retention and saturated hydraulic conductivity. Soil Tillage Res 90:108-116

Mohanty S, Jha MK, Kumar A, Sudheer KP (2010) Artificial neural network modeling for groundwater level forecasting in a River Island of Eastern India. Water Resour Manag 24(9):1845-1865

Moosavi V, Vafakhah M, Shirmohammadi B, Behnia N (2013) A Wavelet-ANFIS hybrid model for groundwater level forecasting for different prediction periods. Water Resour Manag 27(5):1301-1321

Morankar DV, Raju KS, Kumar DN (2013) Integrated sustainable irrigation planning with multiobjective fuzzy optimization approach. Water Resour Manag 27(11):3981-4004

Motaghian HR, Mohammadi J (2011) Spatial estimation of saturated hydraulic conductivity from terrain attributes using regression, kriging, and artificial neural networks. Pedosphere 21(2):170-177

Mustafa MR, Rezaur RB, Saiedi S, Isa MH (2012) River suspended sediment prediction using various multilayer perceptron neural network training algorithms - A case study in Malaysia. Water Resour Manag 26(7): $1879-1897$

Nadiri AA (2007) Water level evaluation in Tabriz underground area by artificial neural networks. MS Theses, University of Tabriz, Iran

Nadiri AA, Asghari MAA, Tsai FTC, Fijani E (2013) Hydrogeochemical analysis for Tasuj plain aquifer, Iran. J Earth Syst Sci 122(4):1091-1105

Naftaly U, Intrator N, Horn D (1997) Optimal ensemble averaging of neural networks. Comput Neural Syst 8: 283-296

Nayak PC, Rao YRS, Sudheer KP (2006) Groundwater level forecasting in a shallow aquifer using artificial neural network approach. Water Resour Manag 20(1):77-90 
Nourani V, Asgharimogaddam A, Nadiri A, Sing VP (2008a) Forecasting spatiotemporal water levels of Tabriz Aquifer. Trend Appl Sci Res 3(4):319-329

Nourani V, Asgharimogaddam A, Nadiri AA (2008b) An ANN-based model for spatiotemporal groundwater level forecasting. Hydrol Process 22:5054-5066

Olatunji SO, Selamat A, Abdulraheem A (2011) Modeling the permeability of carbonate reservoir using type-2 fuzzy logic systems. Comput Ind 62:147-163

Piotrowski AP, Napiorkowski JJ (2011) Optimizing neural networks for river flow forecasting - Evolutionary computation methods versus the Levenberg-Marquardt approach. J Hydrol 407:12-27

Putvance DT (2000) On the electrical-hydraulic conductivity correlation in aquifers. Water Resour Res 36(10): 2905-2913

Research Center of Agriculture and Natural Resources of East Azerbaijan Province (2010) Annual report of water balance of Tasuj plain (in Persian)

Ross J, Ozbek M, Pinder GF (2007) Hydraulic conductivity estimation via fuzzy. Math Geol 39(8):765-780

Safavi HR, Chakraei I, Samani AK, Golmohammadi MH (2013) Optimal reservoir operation based on conjunctive use of surface water and groundwater using neuro-fuzzy systems. Water Resour Manag 27(12):4259-4275

Samani N, Gohari-Moghadam M, Safavi AA (2007) A simple neural network model for the determination of aquifer parameters. J Hydrol 340:1-11

Sanikhani H, Kisi O (2012) River flow estimation and forecasting by using two different adaptive neuro-fuzzy approaches. Water Resour Manag 26(6):1715-1729

Schaap MG, Leij FJ (1998) Using neural networks to predict soil water retention and soil hydraulic conductivity. Soil Tillage Res 47:37-42

Sezer A, Göktepe AB, Altun S (2010) Adaptive neuro-fuzzy approach for sand permeability estimation. Environ Eng Manag J 9(2):231-238

Shirmohammadi B, Vafakhah M, Moosavi V, Moghaddamnia A (2013) Application of several data-driven techniques for predicting groundwater level. Water Resour Manag 27(2):419-432

Siou LK, Johannet A, Borrell V, Pistre S (2011) Complexity selection of a neural network model for karst flood forecasting: the case of the Lez Basin (southern France). J Hydrol 403:367-380

Sugeno M (1985) Industrial application of fuzzy control. North-Holland, New York

Sulaiman M, Shafie A, Karim O, Basri H (2011) Improved water level forecasting performance by using optimal steepness coefficients in an artificial neural network. Water Resour Manag 25(10):2525-2541

Sun J, Zhao Z, Zhang Y (2011) Determination of three dimensional hydraulic conductivities using a combined analytical/neural network model. Tunn Undergr Space Technol 26:310-319

Takagi T, Sugeno M (1985) Identification of systems and its applicationto modeling and control. IEEE Trans Syst Man Cybern 15:116-132

Tamari S, Wosten JHM, Ruiz-Suarez JC (1996) Testing an artificial neural network for predicting soil hydraulic conductivity. Soil Sci Soc Am J 60(6):1732-1741

Tayfur G (2012) Soft computing in water resources engineering. WIT Press, Southampton

Tayfur G, Singh VP (2011) Predicting mean and bankfull discharge from channel cross-sectional area by expert and regression methods. Water Resour Manag 25(5):1253-1267

Tayfur G, Moramarco T, Singh VP (2007) Predicting and forecasting flow discharge at sites receiving significant lateral inflow. Hydrol Process 21(14):1848-1859

Tsai FTC, Li X (2008) Multiple parameterization for hydraulic conductivity identification. Groundwater 46(6): 851-864

Tutmez B (2010) Assessment of porosity using spatial correlation-based radial basis function and neuro-fuzzy inference system. Neural Comput Appl 19:499-505

Tutmez B, Hatipoglu Z (2007) Spatial estimation model of porosity. Comput Geosci 33:465-475

Wolkenhauer O (2001) Fuzzy mathematics in systems theory and data analysis. John Wiley \& Sons, New York, USA

Zadeh LA (1965) Fuzzy sets. Inf Control 8:338-353

Zounemat-Kermani M, Teshnehlab M (2008) Using adaptive neuro-fuzzy inference system for hydrological time series prediction. Appl Soft Comput 8(20):928-936 